\title{
State and trait hopelessness in a prospective five-year study of patients with depressive disorders
}

\section{Baryshnikov, llya}

2018-10-15

Baryshnikov , I , RosenstrÖm , T , Jylha , P , Koivisto , M , Mantere , O , Suominen , K , Melartin , T , Vuorilehto , M , Holma , M , Riihimäki , K \& Isometsä , E T 2018 , ' State and trait hopelessness in a prospective five-year study of patients with depressive disorders ' , Journal of Affective Disorders , vol. 239 , pp. 107-114 . https://doi.org/10.1016/j.jad.2018.07.007

http://hdl.handle.net/10138/304177

https://doi.org/10.1016/j.jad.2018.07.007

publishedVersion

Downloaded from Helda, University of Helsinki institutional repository.

This is an electronic reprint of the original article.

This reprint may differ from the original in pagination and typographic detail.

Please cite the original version. 
Research paper

\title{
State and trait hopelessness in a prospective five-year study of patients with depressive disorders
}

\author{
Ilya Baryshnikov $^{\mathrm{a}}$, Tom Rosenström ${ }^{\mathrm{b}, \mathrm{c}}$, Pekka Jylhäa,d, Maaria Koivisto ${ }^{\mathrm{a}}$, Outi Mantere ${ }^{\mathrm{e}, \mathrm{f}}$, \\ Kirsi Suominen ${ }^{g}$, Tarja Melartin ${ }^{\mathrm{a}}$, Maria Vuorilehto ${ }^{\mathrm{a}}$, Mikael Holma ${ }^{\mathrm{g}}$, Kirsi Riihimäki ${ }^{\mathrm{d}}$, \\ Erkki T. Isometsä ${ }^{\mathrm{a}, \mathrm{d}, *}$
}

a Department of Psychiatry, University of Helsinki and Helsinki University Hospital, Helsinki, Finland

${ }^{\mathrm{b}}$ Department of Mental Disorders, Norwegian Institute of Public Health, Norway

${ }^{\mathrm{c}}$ Department of Psychology and Logopedics, University of Helsinki, Helsinki, Finland

${ }^{\mathrm{d}}$ Mental Health Unit, National Institute of Health and Welfare, Helsinki, Finland

e Department of Psychiatry, McGill University, Montreal, Canada

${ }^{\mathrm{f}}$ Douglas Mental Health University Institute, McGill University, Montreal, Canada

${ }^{\mathrm{g}}$ Department of Mental Health and Substance Abuse, City of Helsinki, Social Services and Health Care, Helsinki, Finland

\section{A R T I C L E I N F O}

\section{Keywords:}

Hopelessness

Depression

Anxiety

Neuroticism

Extraversion

Social support

Suicide

\begin{abstract}
A B S T R A C T
Background: Hopelessness is a common experience of patients with depressive disorders (DD) and an important predictor of suicidal behaviour. However, stability and factors explaining state and trait variation of hopelessness in patients with DD over time are poorly known.

Methods: Patients with DD $(n=406)$ from the Vantaa Depression Study and the Vantaa Primary Care Depression Study filled in the Beck Hopelessness Scale (BHS), Beck Depression Inventory (BDI), Beck Anxiety Inventory (BAI), Perceived Social Support Scale-Revised (PSSS-R), and Eysenck Personality Inventory-Q (EPI-Q) at baseline, at six and eighteen months, and at five years. We conducted a multilevel linear regression analyses predicting BHS with these covariates.

Results: During the five-year follow-up half of the variance in BHS was attributable to between-patient variance $(50.6 \%, \mathrm{CI}=41.2-61.5 \%)$, and the rest arose from within-patient variance and measurement errors. BDI and BAI explained $5.6 \%$ of within-patient and $28.4 \%$ of between-patient variance of BHS. High Neuroticism and low Extraversion explained $2.6 \%$ of the between-patient variance of BHS. PSSS-R explained 5\% of between-patient variance and $1.7 \%$ of within-patient variance of BHS.

Limitations: No treatment effects were controlled.

Conclusions: Hopelessness varies markedly over time both within and between patients with depression; it is both state- and trait-related. Concurrent depressive and anxiety symptoms and low social support explain both state and trait variance, whereas high Neuroticism and low Extraversion explain only trait variance of hopelessness. These variations influence the utility of hopelessness as an indicator of suicide risk.
\end{abstract}

\section{Introduction}

Hopelessness - negative expectation of one's future - is a common experience of patients with depressive disorders (Beck, 1963; Kendler, 2017). Hopelessness plays a central role in two main cognitive theories of depression: Beck's original cognitive theory (Beck, 1963; Beck, 1964) and the hopelessness theory of depression (Abramson et al., 1978). In the original Beck's cognitive theory, hopelessness was a part of the cognitive triad of depression: a negative belief about self, the environment, and the future; and an important risk factor of suicide (Beck,
1964; Kovacs and Beck, 1978). Specifically, Beck et al. (1990) postulated that patients' conceptualization of their situation as untenable leads them to believe that suicide is the only feasible way of dealing with apparently insoluble problems (Beck et al., 1990). Abramson et al. (1978) defined hopelessness as a factor mediating the relation between a stressful event and occurrence of hopelessness depression (Liu et al., 2015). In the hopelessness theory, vulnerable people tend to attribute negative life events to stable and global causes, therefore perceiving that they are "flawed, unworthy, or deficient", which in turn predisposes to suicidal ideation (Abramson et al., 2000).

\footnotetext{
* Corresponding author. Department of Psychiatry, University of Helsinki, P.O. Box 22 FI-00014, Finland.

E-mail address: erkki.isometsa@hus.fi (E.T. Isometsä).
} 
Table 1

Methods used in the Vantaa Depression Study (VDS) and the Vantaa Primary Care Depression Study (PC-VDS).

\begin{tabular}{|c|c|c|}
\hline Cohort & VDS & PC-VDS \\
\hline Timing of screening & 1 Feb 1997 to 31 May 1998 & 1 Jan 2002 to 31 Dec 2002 \\
\hline Catchment area & City of Vantaa (population 169000 in 1997) & $\begin{array}{l}\text { Two districts in the city of Vantaa (population } 63400 \\
\text { in 2002) }\end{array}$ \\
\hline Setting & $\begin{array}{l}\text { Department of Psychiatry of the Peijas Medical Care District, Helsinki University } \\
\text { Central Hospital, Vantaa, Finland }\end{array}$ & $\begin{array}{l}\text { Primary Health Care Organization of the City of } \\
\text { Vantaa, Finland } \\
\text { Three health centres } \\
\text { Two maternity clinics served by } 30 \text { general } \\
\text { practitioners with population-based responsibility }\end{array}$ \\
\hline Target group & $\begin{array}{l}\text { All psychiatric patients aged } 20-59 \text { years } \\
\text { (1) } \\
\text { seeking treatment } \\
\text { (2) } \\
\text { referred to treatment, or } \\
\text { (3) } \\
\text { already in treatment with an acute deteriorating clinical state }\end{array}$ & $\begin{array}{l}\text { Consecutive primary care patients aged } 20-59 \text { years in } \\
\text { general practitioners' waiting room }\end{array}$ \\
\hline Exclusion from screening & ICD-10 schizophrenia, BD I & $\begin{array}{l}\text { Poor general health status prohibiting completion of } \\
\text { screening form }\end{array}$ \\
\hline Screening procedure & $\begin{array}{l}\text { (1) Five screening questions for depression from SCAN, } 1 \text { positive, or } \\
\text { (2) Scale for Suicide Ideation, score } \geq 6\end{array}$ & $\begin{array}{l}\text { (1) PRIME-MD: one positive mood disorders item, } \\
\text { and } \\
\text { (2) Telephone interview: one or more main } \\
\text { symptoms of depression according to SCID-I/P }\end{array}$ \\
\hline Total screened & 806 & 1111 (8 refused) \\
\hline Screened positive & 703 & 402 \\
\hline Refusals & $161(22.9 \%)$ & $37(9.2 \%)$ \\
\hline Diagnostic interview & $\begin{array}{l}\text { After informed consent, DSM-IV (Axis I, SCAN) and DSM-III-R (SCID-II, modified to } \\
\text { DSM-IV) }\end{array}$ & After informed consent DSM-IV (SCID-I/P and SCID-II) \\
\hline Inclusion criteria & DSM-IV MDD with a new depressive episode & DSM-IV depressive disorders \\
\hline Cohort & 269 (46 inpatients, 223 outpatients) & 137 outpatients from primary care \\
\hline $\begin{array}{l}\text { Number of patients at 6- } \\
\text { month follow-up }\end{array}$ & $229(85.1 \%)$ & - \\
\hline $\begin{array}{l}\text { Number of patients at } 18- \\
\text { month follow-up }\end{array}$ & $198(77.3 \%)$ & $92(67.2 \%)$ \\
\hline \multicolumn{3}{|l|}{ 5-year follow-up } \\
\hline Number of Patients & $182(67.7 \%)$ & $112(82.0 \%)$ \\
\hline Switch of diagnosis & $29 \mathrm{BD}, 1$ schizophrenia, 2 schizoaffective disorder & $5 \mathrm{BD}$ \\
\hline $\begin{array}{l}\text { Participants vs. non- } \\
\text { participants }\end{array}$ & $\begin{array}{l}\text { More often female }\left(72.1 \% \text { vs. } 55.6 \%, \chi^{2}=6.581, p=0.010\right) \text {, married or cohabiting } \\
\left(75.6 \% \text { vs. } 59.7 \%, \chi^{2}=7.725, p=0.005\right) \text {, less alcohol dependence at baseline }(39.5 \% \\
\left.\text { vs. } 72.3 \%, \chi^{2}=16.064, p<0.001\right)\end{array}$ & $\begin{array}{l}\text { No difference in age, gender, or baseline depression } \\
\text { severity }\end{array}$ \\
\hline Mean time for interview & 5.2 years & 5.2 years \\
\hline $\begin{array}{l}\text { Diagnostic reliability at } \\
\text { baseline }\end{array}$ & $\begin{array}{l}20 \text { videotaped diagnostic interviews; kappa coefficient for current } \mathrm{MDD}=0.86(95 \% \\
\mathrm{CI}=0.58 \text { to } 1.00) \text {; not tested for comorbidity }\end{array}$ & $\begin{array}{l}20 \text { videotaped diagnostic interviews; kappa coefficient } \\
\text { for current MDD = 1.0; not tested for comorbidity }\end{array}$ \\
\hline
\end{tabular}

MDD = Major Depressive Disorder; PRIME-MD = Primary Care Evaluation of Mental Disorders; SCID-I/P = Structured Clinical Interview for DSM-IV Axis I Disorders, research version, patient edition with psychotic screen; SCID-II = Structured Clinical Interview for DSM-IV Personality Disorders; WHO SCAN = World Health Organization Schedules for Clinical Assessment in Neuropsychiatry, version 2.0

Both theories have been empirically tested (see e.g. Beck et al., 1979; Abramson et al., 2000 for reviews), partly overlap (Possel and Thomas, 2011), and postulate hopelessness to represent a link between depression and suicide.

Derived from Beck's original cognitive theory of depression, hopelessness is further identified as one of the central risk factors for suicide in numerous epidemiological studies (Beck et al., 1990). However, while it is one of the established risk factors for suicide deaths among subjects with depression (Hawton et al., 2013), recent meta-analyses of risk factors for suicide following self-harm (Chan et al., 2016) or suicidal behaviour (Carter et al., 2017) have questioned the predictive value of hopelessness (Ribeiro et al., 2018). There are multiple reasons for poor predictive validity of measures in predicting suicidal acts, but one neglected aspect is temporal variability. For any risk factor for suicide, it is crucial to know the extent of which it is trait-related and situationally specific (i.e. state-related) (Kraemer et al., 1997). A trait factor may represent vulnerability for suicide and can be used to identify patients at risk regardless of the time of the measurement. A state factor, representing a disorder-related characteristic, is measurable only during the course of the disorder (Kraemer et al., 1994). Thus, unlike with temporally stable, trait-like risk factors, timing of measurement may be crucial for obtaining valid estimates of risk in case of temporally variable, state-related risk factors. Consequently, it is important to know the degree to which hopelessness represents trait- or state-like characteristics among patients with depression.

To our knowledge, only one study on state and trait characteristics of hopelessness in a clinical sample exists. Young et al. (1996) demonstrated that patients with depression had a baseline level of hopelessness when not depressed, and an increment in hopelessness attributable to both the severity of depression at the time and an individual-specific sensitivity to hopelessness in depression. The authors postulated that baseline hopelessness and individual sensitivity to hopelessness in depression represent trait components of hopelessness, whereas the increment due to depression symptoms represents a state component of hopelessness (Young et al., 1996).

Factors explaining the state and trait variation of hopelessness are only partly known. In Beck's cognitive theory of depression (1963, 1986), hopelessness, emerging during depressive episodes, constitutes a cognitive schema of a depressed person (Beck and Haigh, 2014). However, Young et al. (1996) found that severity of depression only partially explained state hopelessness, the intensity of which varied from person to person at the same level of depression.

Personality traits may underlie trait hopelessness. In the framework of the five-factor model of personality (Costa, 1991), high Neuroticism is a general vulnerability factor for the development of internalizing disorders, whereas low Extraversion relates more specifically to 
depression (Clark et al., 1994). Young et al. (1996) found that only low Extraversion, but not high Neuroticism, predicted trait hopelessness. Another study showed that both high Neuroticism and low Extraversion predicted hopelessness in a student sample (Chioqueta and Stiles, 2005). Thus, the relationship between personality traits and trait hopelessness remains to be clarified. Furthermore, Panzarella et al. (2006) supposed that social support may reduce the cognitive vulnerability to depression by decreasing trait hopelessness. However, we are not aware of any longitudinal study examining the role of social support in state and trait variations of hopelessness among patients with depressive disorders.

The aim of our observational study was to assess a) the degree to which hopelessness, experienced by patients with depressive disorders during a five-year follow up, represents a situational phenomenon (state variance) as opposed to a stable cognitive vulnerability trait (trait variance); and b) the extent that depression and anxiety symptoms, Extraversion and Neuroticism, and social support explain state versus trait hopelessness. We hypothesized that depressive and anxiety symptoms are specifically associated with state variation of hopelessness, personality traits with trait variation of hopelessness, and social support with both state and trait variation of hopelessness.

\section{Methods}

\subsection{Vantaa Depression Study (VDS) and Vantaa Primary Care Depression Study (PC-VDS)}

Patients came from two separate but comparable cohorts - VDS and PC-VDS. Both are the collaborative research projects of the Mood Disorder Research Unit of the Department of Mental Health and Substance Use of the National Institute of Health and Welfare, Helsinki, Finland. The pertinent ethics committee approved the research protocols. The methodologies of the studies are presented in Table 1 and have been described in more detail elsewhere - for VDS (Holma et al., 2008; Melartin et al., 2002) and for PC-VDS (Riihimaki et al., 2014).

\subsection{Patients}

Altogether 1917 primary care or psychiatric patients were screened for acute depressive states (PC-VDS) or major depressive disorder (MDD) (VDS). Patients were fully informed about the study and gave written informed consent. In PC-VDS, two-thirds of the patients had MDD, and the rest had dysthymia, currently subsyndromal but lifetime MDD, or true minor depression.

The final baseline dataset included 269 MDD patients (VDS) and 137 depressive disorder patients (PC-VDS) (total $n=406$ ), sampled at four occasions (comprising 1624 observations altogether). Sociodemographic characteristics of the patients are shown in Table 2. Our main aim was to test how different covariates affect the state-trait decomposition of hopelessness, and therefore, we removed any possibility of missing data (and imputation) -related confounding by excluding all records of patients with any missing values in any of the covariates. This resulted in a data frame of 1099 observations.

However, a sensitivity analysis with (multilevel) imputed data using "jomo" R package, version 2.6-2, did not indicate serious bias due to missing values (see supplementary material, page 4 and Supplementary Table 2).

\section{Baseline and follow-up evaluation}

\subsection{Baseline assessment}

Full DSM-IV axis I diagnoses (SCID-I/P in PC-VDS; SCAN in VDS) and axis II diagnoses (SCID-II for DSM-IV in PC-VDS; SCID-II for DSMIII-R in VDS) were made. Interrater agreement in diagnostic interviews was excellent (kappa 0.86-1.00) (Melartin et al., 2002, Vuorilehto et al., 2005).

\subsection{Follow-up assessment}

After baseline assessments, patients were interviewed at 6 (VDS) and 18 months (VDS and PC-VDS) and at 5 years (VDS and PC-VDS).

\subsection{Scales}

We collected the following self-reported scales at both baseline and all follow-up assessments: the Beck Hopelessness Scale, BHS (Beck et al., 1974), the Perceived Social Support Scale-Revised, PSSS-R (Blumenthal et al., 1987), the 21-item Beck Depression Inventory, BDI (BECK et al, 1961), and the 21-item Beck Anxiety Inventory, BAI (Beck et al., 1988). In addition, we administrated the 17-item Hamilton Depression Scale, HAM-D (HAMILTON, 1960) at all-time points. Personality was assessed with Eysenck Personality Inventory -Q (EPI-Q), a short measure based on EPI (Eysenck and Eysenck, 1964). EPI-Q comprises 18 items, 9 of the EPI's original 24 neuroticism items and 9 of the original 24 extraversion items.

\section{Statistical methods}

We estimated linear mixed-effects (a.k.a. multilevel) models ("lme4" package, version 1.1-12) using $R$ software version 3.3.2 (Bates et al., 2015). A mixed-effect model consists of both fixed and random effects. A fixed-effect regression coefficient $\beta$ refers to a usual regression coefficient. A random-effect regression coefficient $\gamma_{j}$ is an effect on the outcome for an individual $i\left(\beta+\gamma_{j}\right) x$, and it varies over individuals. Only the variance of $\gamma_{i}$ s across individuals can be estimated and is denoted here by $\sigma_{\gamma}$. If $x=1$ for all individuals and time points, then $\gamma_{j}$ is also called the random intercept and captures the between-individual variance in the outcome. The remaining error variance not captured by any other fixed or random effect is the within-individual error variance, $\sigma_{\mathrm{W}}$, which includes everything left unexplained by the model covariates.

The multilevel structure of our data derives from multiple assessments of the same individuals. Thus, a linear mixed-effect model equation may be written as

$y_{i}=\beta_{0}+\beta_{1} x_{i}+\gamma_{j[i]} x_{i}+\zeta_{j[i]}+\varepsilon_{i}$,

where $y_{i}$ represents one observation of the long-form data and $j[i]$ indexes repeated assessment of the same participant. The terms $\beta_{0}$ and $\beta_{1}$ refer to the fixed-effect regression coefficients, and $\varepsilon_{i}$ is the residual term. In addition, we have a random-effect intercept/residual $\zeta_{j[i]}$, which is fixed within individual $j$, the subject of the observation, but varies across individuals. Consequently, its variance captures the part of the residual variance that is due to stable between-individual differences and is denoted here by $\sigma_{B}$. The remaining residual variance $\varepsilon_{i}$ is attributable to within-individual change and errors of measurement and is denoted by $\sigma_{W}$.

Alternatively, $\sigma_{B}$ and $\sigma_{W}$ can be regarded as different types of residual variances. Addition of a time-varying fixed effect can reduce either type of residual variation, or both. We were specifically interested in what type of residual variation certain fixed covariates reduce or explain. The concept of coefficient of determination, or $R^{2}$, is a counterpart to residual variance, quantifying the proportion of variance explained by fixed effects, rather than that left unexplained. Linear mixed-effects models (LMM) can explain two types of variance (Nakagawa and Schielzeth, 2013). In addition to marginal variance explained $\left(R_{L M M(m)}^{2}\right)$ by the fixed-effect covariates, there is also the conditional variance explained $\left(R_{L M M(c)}^{2}\right)$ when holding $\gamma_{i j}$ constant; $R_{L M M(c)}^{2}$ equivalently refers to all outcome variance explained by both random and fixed effects. Fixed covariates that explain trait variance increase the marginal $R_{L M M(m)}^{2}$, but do not necessarily affect the 
Table 2

Sociodemographic characteristics, and mean scores and standard deviations (SD) of Scale for Suicidal Ideation (SSI), Beck Depression Inventory (BDI), Beck Anxiety Disorder (BAI), Hamilton Rating Scale for Depression (HAM-D), Beck Hopelessness Scale (BHS) and Perceived Social Support Scale -Revised (PSSS-R) in Vantaa Depression Study (VDS, $n=269$ ) and Vantaa Primary Care Depression Study (PC-VDS, $n=137$ ).

\begin{tabular}{|c|c|c|c|c|c|c|}
\hline & \multicolumn{2}{|c|}{ VDS $(n=269)$} & \multicolumn{2}{|c|}{ PC-VDS $(n=137)$} & \multirow[b]{2}{*}{$\chi^{2}$} & \multirow[b]{2}{*}{$\mathrm{p}$} \\
\hline & $\mathrm{n}$ & $\%$ & $\mathrm{n}$ & $\%$ & & \\
\hline Gender & & & & & & ns \\
\hline Female & 197 & 73.2 & 104 & 75.9 & & \\
\hline Male & 72 & 26.8 & 33 & 24.1 & & \\
\hline Education $^{\mathrm{a}}$ & & & & & & ns \\
\hline $\begin{array}{l}\text { University or } \\
\text { polytechnic }\end{array}$ & 92 & 34.3 & 44 & 34.4 & & \\
\hline Vocational & 69 & 25.6 & 35 & 27.4 & & \\
\hline None & 108 & 40.1 & 49 & 38.2 & & \\
\hline Marital status ${ }^{b}$ & & & & & & ns \\
\hline $\begin{array}{l}\text { Married or } \\
\text { cohabiting }\end{array}$ & 135 & 50.2 & 72 & 55 & & \\
\hline Single & 134 & 49.8 & 59 & 45 & & \\
\hline Work status ${ }^{c}$ & & & & & 39.903 & $<0.001$ \\
\hline Employed & 194 & 73.5 & 83 & 61.0 & & \\
\hline Unemployed & 57 & 21.5 & 27 & 20.0 & & \\
\hline $\begin{array}{l}\text { Disability pension } \\
\text { or retired }\end{array}$ & 13 & 5.0 & 27 & 19.0 & & \\
\hline \multicolumn{7}{|l|}{ Comorbid disorders } \\
\hline \multicolumn{7}{|l|}{ Evaluated at baseline } \\
\hline Any anxiety disorder & 152 & 56.5 & 59 & 43.1 & 6.569 & 0.012 \\
\hline $\begin{array}{l}\text { Alcohol dependence, } \\
\text { current }\end{array}$ & 38 & 14.1 & 6 & 4.4 & 8.924 & 0.002 \\
\hline \multirow{2}{*}{$\begin{array}{l}\text { Any personality } \\
\text { disorder, current }\end{array}$} & 118 & 43.9 & 71 & 51.8 & & ns \\
\hline & Mean & SD & Mean & SD & $\mathrm{t}$ & $\mathrm{p}$ \\
\hline Age, bl & 39.7 & 11.1 & 45.3 & 13.7 & -4.435 & $<0.001$ \\
\hline BDI, bl & 27.6 & 8.6 & 19.3 & 10.0 & 8.799 & $<0.001$ \\
\hline BDI, 6 months ${ }^{\mathrm{i}}$ & 12.7 & 10.0 & 15.0 & 11.4 & -1.984 & 0.048 \\
\hline BDI, 18 months ${ }^{1}$ & 11.4 & 10.4 & 12.9 & 11.0 & & ns \\
\hline BDI, 5 years ${ }^{\mathrm{m}}$ & 10.7 & 10.5 & 14.4 & 11.2 & -2.856 & 0.005 \\
\hline $\mathrm{BAI} \mathrm{bl}^{\mathrm{d}}$ & 22.4 & 10.6 & 17.0 & 12.6 & 4.485 & $<0.001$ \\
\hline BAI, 6 months ${ }^{\mathrm{i}}$ & 13.7 & 10.6 & & & & \\
\hline BAI, 18 months $^{j}$ & 11.6 & 10.5 & 14.7 & 12.0 & -2.464 & 0.014 \\
\hline BAI, 5 years ${ }^{\mathrm{k}}$ & 13.1 & 10.8 & 13.6 & 12.5 & & ns \\
\hline $\mathrm{BHS}, \mathrm{bl}^{\mathrm{e}}$ & 10.3 & 4.8 & 8.8 & 5.3 & 2.859 & 0.004 \\
\hline BHS, 6 months $^{\mathrm{f}}$ & 7.9 & 5.2 & & & & \\
\hline BHS, 18 months ${ }^{g}$ & 7.4 & 5.2 & 7.6 & 5.8 & & ns \\
\hline BHS, 5 years $^{\mathrm{h}}$ & 6.3 & 4.7 & 7.4 & 5.3 & & ns \\
\hline HAM-D, bl & 19.3 & 6.2 & 16.1 & 5.3 & 8.399 & $<0.001$ \\
\hline HAM-D, 6 months ${ }^{\mathrm{i}}$ & 9.2 & 7.7 & & & & \\
\hline HAM-D, 18 months $^{j}$ & 8.3 & 7.4 & 9.8 & 6.9 & & $\mathrm{~ns}$ \\
\hline HAM-D, 5 years ${ }^{\mathrm{n}}$ & 10.0 & 8.5 & 11.3 & 7.9 & & ns \\
\hline PSSS-R, bl ${ }^{\circ}$ & 39.1 & 12.8 & 43.0 & 12.6 & -2.876 & 0.004 \\
\hline PSSS-R, 6 months ${ }^{\mathrm{i}}$ & 42.6 & 12.6 & & & & \\
\hline PSSS-R, 18 months $^{\mathrm{p}}$ & 42.5 & 13.6 & 45.7 & 12.4 & -1.986 & 0.048 \\
\hline PSSS-R, 5 years ${ }^{\mathrm{r}}$ & 42.3 & 12.9 & 47.0 & 12.5 & -2.995 & 0.003 \\
\hline
\end{tabular}

a missing data $9 / 137$,

b missing data $6 / 137$,

c missing data 5/269,

d missing data $1 / 269,4 / 137$,

e missing data $1 / 269,5 / 137$,

f missing data 94/269,

g missing data 42/269, 35/137,

h missing data 112/269, 29/137,

i missing data 40/269,

j missing data 62/269,11/137,

k missing data 86/269, 27/137,

1 missing data $63 / 269$,

$\mathrm{m}$ missing data $80 / 269,27 / 137$,

n missing data $81 / 269,26 / 137$,

o missing data $1 / 269,7 / 137$,

p missing data 62/269, 35/137,

$\mathrm{r}$ missing data 84/269, 33/137,

${ }^{\mathrm{s}}$ missing 1/269,

${ }^{\mathrm{t}}$ missing data $118 / 269$,

umissing data 69/269 
conditional $R_{L M M(c)}^{2}$ because it already includes the trait variance.

We compared models with and without different model components using likelihood-ratio tests. Ninety-five percent likelihood-profile confidence intervals (CIs) were presented for the individual model components. We standardized the outcome variable to have unit variance and zero mean in the long-data format (i.e., across all observations), except for binary outcomes. Continuous exposure (i.e., 'independent') variables were standardized to facilitate interpretation of effect sizes from regression coefficients.

\section{Results}

\subsection{Correlation analyses}

Spearman's correlations between BHS and BDI (hopelessness item excluded) total scores varied between 0.47 and $0.7(p<0.001)$ at the four time points (see Supplementary Table 1 and Supplementary Figs. 1-4).

\subsection{Baseline model for hopelessness}

Half of the variance in hopelessness across all cohorts and followups was due to stable between-patient differences $(50.6 \%$, $\mathrm{CI}=41.2-61.5 \%$ ), and the rest due to within-patient change and measurement errors. There was a significant decreasing time trend in hopelessness after the study baseline $\left(\beta_{\mathrm{t} 1}=-0.39, \beta_{\mathrm{t} 2}=-0.42\right.$, $\beta_{\mathrm{t} 3}=-0.53$, with subscript $\mathrm{tn}_{\mathrm{t}}$ denoting the $\mathrm{n}^{\text {th }}$ follow-up after baseline) (Table 3 ). We then assessed whether different covariates were associated with between- and/or within-patient variance by comparing the baseline model estimates with models that include a specific covariate set.

\subsection{Effects of depression and anxiety on hopelessness variance partition}

Depressive symptoms had a highly significant fixed effect on hopelessness, irrespective of whether assessed by BDI or HDS. However, the random-effect slope of BDI was non-significant $\left(\chi^{2}=4.53\right.$, d.f. $=2$, $p=0.104)$, as was that of HDS $\left(\chi^{2}=4.94, p=0.085\right)$, meaning that individuals were not found to be heterogeneous in how their depressive

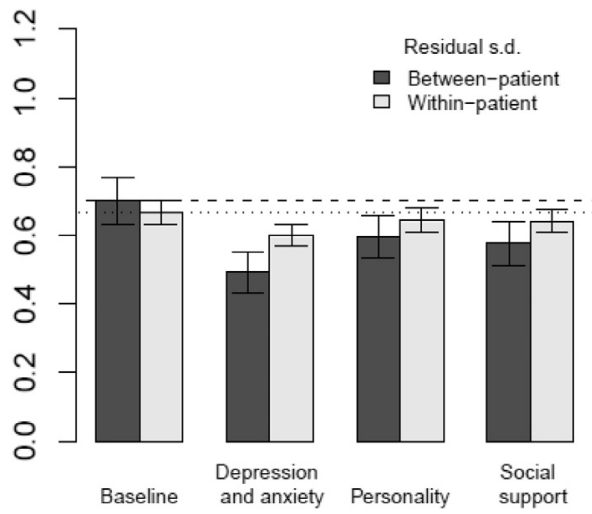

Fig. 1. Standard deviances (s.d.) of the residuals of the linear mixed regression model explaining variance of hopelessness. Whiskers represent $95 \%$ likelihoodbased confidence intervals, the dashed line the baseline between-patient residual standard deviance, and the dotted line the baseline within-patient residual standard deviance.

symptoms related to their hopelessness. The same held for anxiety symptoms assessed by BAI ( $\left.\chi^{2}=0.298, p=0.862\right)$. Furthermore, when all BDI, HDS, and BAI were included in the same model, the fixed effect of HDS was no longer statistically significant $(\beta=-0.054$, $\mathrm{CI}=-0.13-0.02$ ). Table 3 shows how the baseline model changes when including BDI and BAI in the model, whereas Fig. 1 illustrates standard deviations of the between- and within-patient residuals across the covariate conditions.

\subsection{Effects of personality on hopelessness variance partition}

Extraversion had a significant random-effect slope on hopelessness $\left(\chi^{2}=6.49\right.$, d.f. $\left.=2, p=0.039\right)$, whereas neuroticism did not reach statistical significance: $\left(\chi^{2}=5.18, p=0.075\right)$. The random-effect slope of extraversion reached statistical significance because of its strong negative correlation with the random-effect intercept $[r=-0.71$, $\mathrm{CI}=(-1,-0.17)]$. In other words, the strength of the extraversion-tohopelessness association varied negatively with within-individual (state) fluctuations in hopelessness, adding 0.11 s.d. units of between-

Table 3

Multilevel linear regression models predicting hopelessness.

\begin{tabular}{|c|c|c|c|c|c|c|c|c|c|c|c|c|c|}
\hline \multirow[t]{2}{*}{ Effect type } & \multirow[t]{2}{*}{ Variable } & \multicolumn{3}{|c|}{ Model I } & \multicolumn{3}{|l|}{ Model II } & \multicolumn{3}{|l|}{ Model III } & \multicolumn{3}{|l|}{ Model IV } \\
\hline & & $\beta$ & CI low & CI upp & $\beta$ & CI low & CI upp & $\beta$ & CI low & CI upp & $\beta$ & CI low & CI upp \\
\hline \multirow[t]{11}{*}{ Fixed } & Intercept & 0.22 & 0.12 & 0.33 & -0.170 & -0.270 & -0.08 & -0.139 & -0.231 & -0.047 & -0.097 & -0.186 & -0.007 \\
\hline & Sex (male) & 0.32 & 0.13 & 0.50 & 0.300 & 0.160 & 0.44 & 0.247 & 0.110 & 0.385 & 0.151 & 0.018 & 0.284 \\
\hline & Follow-up 1 & -0.38 & -0.51 & -0.24 & 0.220 & 0.094 & 0.36 & 0.193 & 0.062 & 0.324 & 0.162 & 0.034 & 0.290 \\
\hline & Follow-up 2 & -0.41 & -0.52 & -0.31 & 0.200 & 0.089 & 0.31 & 0.178 & 0.069 & 0.289 & 0.153 & 0.046 & 0.261 \\
\hline & Follow-up 3 & -0.54 & -0.66 & -0.43 & 0.068 & -0.047 & 0.18 & 0.029 & -0.087 & 0.146 & 0.005 & -0.108 & 0.120 \\
\hline & BDI & - & - & - & 0.480 & 0.410 & 0.54 & 0.435 & 0.366 & 0.506 & 0.385 & 0.316 & 0.454 \\
\hline & BAI & - & - & - & 0.150 & 0.085 & 0.21 & 0.118 & 0.056 & 0.181 & 0.103 & 0.042 & 0.164 \\
\hline & Extraversion & - & - & - & - & - & - & -0.113 & -0.166 & -0.060 & -0.079 & -0.131 & -0.027 \\
\hline & Neuroticism & - & - & - & - & - & - & 0.064 & 0.008 & 0.121 & 0.049 & -0.006 & 0.104 \\
\hline & Social support & - & - & - & - & - & - & - & - & - & -0.218 & -0.272 & -0.164 \\
\hline & & $\sigma$ & CI low & CI upp & $\sigma$ & CI low & CI upp & $\sigma$ & CI low & CI upp & $\sigma$ & CI low & CI upp \\
\hline \multirow[t]{3}{*}{ Random } & Between & 0.490 & 0.400 & 0.590 & 0.243 & 0.1900 & 0.3000 & 0.223 & 0.170 & 0.279 & 0.195 & 0.147 & 0.245 \\
\hline & Within & 0.445 & 0.400 & 0.490 & 0.361 & 0.3200 & 0.4000 & 0.360 & 0.322 & 0.398 & 0.349 & 0.312 & 0.385 \\
\hline & & $\mathbf{R}^{2}$ & & & $\mathbf{R}^{2}$ & & & $\mathbf{R}^{2}$ & & & $\mathbf{R}^{2}$ & & \\
\hline \multirow[t]{2}{*}{$\mathrm{R}_{\mathrm{LMM}}^{2}$} & Marginal & 0.070 & - & - & 0.354 & - & - & 0.380 & - & - & 0.430 & - & - \\
\hline & Conditional & 0.558 & - & - & $\begin{array}{l}0.614 \\
\Delta \mathbf{R}^{2}\end{array}$ & - & - & $\begin{array}{l}0.617 \\
\Delta \mathbf{R}^{2}\end{array}$ & - & - & $\begin{array}{l}0.634 \\
\Delta \mathbf{R}^{2}\end{array}$ & - & - \\
\hline \multirow[t]{2}{*}{$\Delta \mathrm{R}_{\mathrm{LMM}}^{2}$} & Marginal & - & - & - & 0.284 & - & - & 0.310 & - & - & 0.360 & - & - \\
\hline & Conditional & - & - & - & 0.056 & - & - & 0.059 & - & - & 0.076 & - & - \\
\hline
\end{tabular}

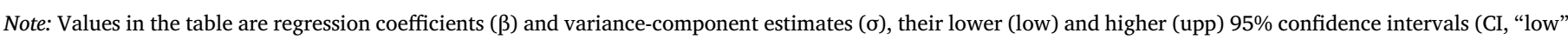

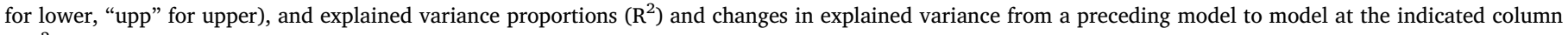

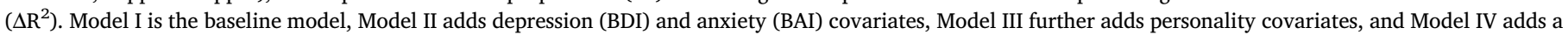
covariate for perceived social support. 
individual variance to the estimated fixed-effect, i.e., to $\beta=-0.259$, $\mathrm{CI}=(-0.32,-0.20)$. The random-effect slope was not only confounded with intercept but also had a negligible effect on explained variance, however, and was therefore omitted from further models for simplicity. The fixed-effect regression of hopelessness on neuroticism was estimated at $\beta=0.311, \mathrm{CI}=(0.26,0.37)$. As expected, the personality covariates alone explained a portion of between-patient variation in the data, but little within-patient variation (Fig. 1). Adjusting for depression and anxiety attenuated effects of personality traits, but they remain significant contributors to the model (Table 3).

\subsection{Effects of perceived social support on hopelessness variance partition}

Perceived social support had a nearly significant random-effect slope on hopelessness $\left(\chi^{2}=5.67\right.$, d.f. $=2, p=0.059$ ), but this "near hit" vanished after constraining its near perfect negative correlation (confounding) with the random intercept to zero $\left(\chi^{2}=0.30\right.$, d.f. $=1$, $p=0.584)$. We excluded the random slope from the model, but the fixed effect of perceived social support $[\beta=-0.407, \mathrm{CI}=(-0.46$, $-0.35)$ ] was a statistically significant explanation for the betweenpatient variance in hopelessness (Fig. 1). Furthermore, it significantly added to the model including depression, anxiety, and extraversion and neuroticism personality traits $\left(\chi^{2}=60.02\right.$, d.f. $=1, \quad p<0.001$; Table 3).

\section{Discussion}

In this observational five-year prospective study on 406 patients with depressive disorders, we found that patients with depressive disorders demonstrate both depression-related hopelessness and stable, trait-like hopelessness to an equal quantitative degree. Symptoms of depression and anxiety were substantial covariates of both state and trait variance of hopelessness. Personality traits of Neuroticism and Extraversion both partially underlie a trait component of hopelessness. Finally, perceived social support significantly predicted hopelessness, explaining both state and trait variation of hopelessness.

This study has several strengths. First, to our knowledge, this is the first study reporting the quantitative degree of state and trait variance of hopelessness in patients with depressive disorder during a five-year follow-up. Second, our study is the first to investigate the predictive value of symptoms of depression and anxiety, personality traits, and social support in state and trait variation of hopelessness. Third, we used the mixed-effects linear regression analysis, which allowed as to estimate both within- and between-patient differences in hopelessness. Fourth, we gathered extensive data on self-reported symptoms of depression and anxiety as well as Neuroticism and Extraversion and perceived social support at four time points. This allowed us to evaluate the extent to which these covariates affect self-reported hopelessness in a dynamic manner. Fifth, the two cohorts cover a relatively large and regionally representative number of patients with depressive disorders, and both the cohorts employed similar methodologies, allowing their valid comparisons and pooling of data. Sixth, we assessed the depression symptoms using both the self-reported BDI and HAM-D, administered by a health care professional. This allowed us to rule out some of the potential bias related to self-report. Seventh, we verified the clinical diagnoses in structured clinical diagnostic interviews. Seventh, we conducted the sensitivity analysis with and without the imputation method. No significant bias related to missing values emerged.

Nevertheless, the study also has limitations. First, individual-specific treatment effects were not controlled, although an average trend of recovery was taken into account. Specific treatments received by the patients could have differentially influenced the degree of hopelessness by reducing severity of symptoms of depression and anxiety. Second, the patients repeatedly filled in the self-report questionnaires during mood-disorder episodes, which could have been affected by impairments in social cognition (Hoertnagl and Hofer, 2014), autobiographical memory disruptions (Talarowska et al., 2016), and distortions in self-reflection (Philippi and Koenigs, 2014). However, these self-report tools are widely used in clinical settings despite their potential limitations. Third, personality was assessed with the Eysenck Personality Inventory, as more modern scales such as the NEO FiveFactor Inventory (Costa and McCrae, 1992) were not available in Finnish at the time that the follow-up study commenced. However, the correlation of neuroticism and extraversion dimensions between EPI and NEO has been found to be high ( $r=0.77$ for both dimensions) (Aluja et al., 2002). Fifth, we measured hopelessness in patients who already had a depressive disorder. Hence, we were unable to conclude whether trait hopelessness represents a characteristic existing before a first depressive episode, as Abramson et al (1989) suggested, or a "scars" phenomenon (Zeiss and Lewinsohn, 1988).

We showed that patients with depressive disorder demonstrate both state and trait characteristics of hopelessness during the five-year follow-up. More specifically, half of the variance in hopelessness was attributable to trait and half to state components of hopelessness. Depressive symptoms affected both components. Young et al. (1996) demonstrated similar substantial stability and variability of hopelessness in patients with depressive disorder. The same is also true for bipolar disorder (Valtonen et al., 2009). Thus, among patients with depressive disorders, hopelessness appears to comprise partly an enduring experience, partly a negative view of the future, waxing and waning in tandem with depressive mood.

Depression and anxiety symptoms explained $5.6 \%$ of the withinpatient variation in hopelessness. This is consistent with Beck's cognitive theory, assuming that hopelessness may be an indicator of the severity of depression (Beck, 1963). Moreover, in line with the findings of Young et al. (1996), we showed that some depressed patients seem to experience more hopelessness than others, even at the same degree of depressive sympt0ms. Thus, the degree of hopelessness tends to increase during a depressive episode and decrease in remission. For instance, for 56 persons recovered from depression at 6 months, the degree of hopelessness measured by BHS significantly decreased from 8.5 to 5.3 (data available on request), even though it did not disappear. Consequently, in terms of suicide, the predictive value of hopelessness measured when an individual is not depressed is probably lower than when an individual is depressed. This notable temporal variability of hopelessness should be taken into account when assessing its predictive value. In addition, it is important to note that not all depressed patients are equally hopeless. As our Supplementary Figures demonstrate, it is quite possible to be clinically depressed without being significantly hopeless, or vice versa.

Young et al. (1996) showed that more extensive trait hopelessness was associated with several negative outcomes, including the more frequent occurrences of depression and suicide attempts. In our study, symptoms of depression and anxiety explained $28.4 \%$ of trait variance of hopelessness, indicating that patients with more extensive trait hopelessness tend to experience more depression and anxiety symptoms, and vice versa.

Patients with depressive disorders tend to demonstrate hopelessness even when not depressed. High Neuroticism and low Extraversion were statistically significant predictors of hopelessness, explaining $2.6 \%$ of the between-patient variance of hopelessness. This finding is consistent with the studies of Chioqueta et al. (2005) and Bayrami et al. (2012) on student samples. High Neuroticism and low Extraversion are also associated with more severe depression and anxiety symptoms (Xia, et al., 2011) and more time spent depressed. Therefore, high Neuroticism and low Extraversion may partially underlie the trait component of hopelessness, which is, in turn, associated with more severe internalizing pathology.

Finally, social support explained $5 \%$ of variance of trait hopelessness and $1.7 \%$ of state hopelessness. This finding is in line with the expanded hopelessness theory of depression (Panzarella et al., 2006), which postulates that adaptive inferential feedback, a subtype of social 
support, might reduce trait hopelessness by decreasing negative inferential styles and the likelihood of making maladaptive inferences about negative life events. As low social support is a well-acknowledged risk factor of suicidal behaviour (O'Connor and Nock, 2014), the degree of hopelessness may play a mediational role between them.

Overall, the patients with depressive disorders show a notable temporal variability of the degree of hopelessness, which aggravates during depression and weakens after recovery. This temporal instability is an essential consideration when assessing the association between experienced hopelessness and risk for suicide. In addition, as state hopelessness is markedly influenced by symptoms of depression and anxiety, their effective treatment may alleviate the degree of hopelessness and risk of suicidal acts. Further studies on the association between perceived social support, hopelessness and risk of suicide are needed.

\section{Conclusions}

In the five-year follow-up, patients with depressive disorders demonstrated an enduring experience of hopelessness, the intensity of which varied within and between patients. The degree of hopelessness tends to escalate during depression and weaken after recovery, even though it does not disappear. Furthermore, not all depressed patients are equally hopeless. Symptoms of depression and anxiety substantially explain both trait and state hopelessness. Trait hopelessness is partially attributable to personality traits such as high Neuroticism and low Extraversion. In addition, social support explains both state and trait variance of hopelessness. The marked temporal variability of hopelessness influences the predictive value of hopelessness as a risk factor for suicide.

\section{Declaration of interest}

None.

\section{Conflict of interest}

None.

\section{Foundation and acknowledgments}

State and trait hopelessness in a prospective five-year study of patients with depressive disorders

1. Ilya Baryshnikov, MD (2)

2. Tom Rosenström, $\mathrm{PhD}(3)$

3. Pekka Jylhä, $\mathrm{MD}, \mathrm{PhD}(1,2)$

4. Maaria Koivisto, MD (2)

5. Outi Mantere, MD, $\mathrm{PhD}(5,6)$

6. Kirsi Suominen, MD, $\mathrm{PhD}(1,4)$

7. Tarja Melartin, MD, $\mathrm{PhD}(1,2)$

8. Maria Vuorilehto, MD, PhD (1)

9. Mikael Holma, MD, PhD (1)

10. Kirsi Riihimäki, $\mathrm{MD}, \mathrm{PhD}(1)$

11. Erkki T. Isometsä, $\mathrm{MD}, \mathrm{PhD}(1,2)$

(1) Mental Health Unit, National Institute of Health and Welfare, Helsinki, Finland

(2) University of Helsinki and Helsinki University Hospital, Department of Psychiatry, Helsinki, Finland

(3) Department of Mental Disorders, Norwegian Institute of Public Health, Norway, and Department of Psychology and Logopedics, University of Helsinki, Helsinki, Finland

(4) City of Helsinki, Social Services and Health Care, Department of Mental Health and Substance Abuse, Helsinki, Finland

(5) Faculty of Medicine, McGill University, Montreal, Canada

(6) Douglas Mental Health University Institute, McGill University, Montreal, Canada
Nobody besides the researchers had a role in study design; in the collection, analysis and interpretation of data; in the writing of the report; or in the decision to submit the paper for publication

Authors $(1,2,3)$ managed the literature searches and drafted the manuscript. Authors $(3,5,6,7,8,9,10,11)$ designed the study. Authors $(1,2)$ undertook the statistical analyses. Authors $(2,3,4,5,6$, $7,8,9,10,11)$ supervised the writing of the manuscript. Authors (2-11) provided expert methodological and conceptual comments. All authors (1-12) have critically read and commented on the manuscript, and approved the final version.

\section{Supplementary materials}

Supplementary material associated with this article can be found, in the online version, at doi:10.1016/j.jad.2018.07.007.

\section{References}

Abramson, L.Y., Seligman, M.E., Teasdale, J.D., 1978. Learned helplessness in humans: critique and reformulation. J. Abnorm. Psychol. 87, 49-74.

Abramson, L.Y., Alloy, L.B., Hogan, M.E., Whitehouse, W.G., Gibb, B.E., Hankin, B.L., Cornette, M.M., 2000. The hopelessness theory of suicidality. The Hopelessness Theory of Suicidality. Kluwer Academic/Plenum Publishers, New York, NY, US, pp. 17-32.

Aluja, A., López, O.G., Garcia, L.F., 2002. A comparative study of Zuckerman's three structural models for personality through the NEO-PI-R, ZKPQ-III-R, EPQ-RS and Goldberg's 50-bipolar adjectives. Personal. Indiv. Diff. 33, 713-725.

Bates, D., Máchler, M., Bolker, B., Walker, S., 2015. Fitting linear mixed-effects models using lme4. J. Statis. Softw. 67.

Beck, A.T., Ward, C.H., Mendelson, M., Mock, J., Erbaugh, J., 1961. An inventory for measuring depression. Arch. Gen. Psychiatry. 4, 561-571.

Beck, A.T., 1963. Thinking and depression. I. Idiosyncratic content and cognitive distortions. Arch. Gen. Psychiatry 9, 324-333.

Beck, A.T., 1964. Thinking and depression: Ii. theory and therapy. Arch. Gen. Psychiatry $10,561-571$.

Beck, A.T., Weissman, A., Lester, D., Trexler, L., 1974. The measurement of pessimism: the hopelessness scale. J. Consult. Clin. Psychol. 42, 861-865.

Beck, A.T., Epstein, N., Brown, G., Steer, R.A., 1988. An inventory for measuring clinical anxiety: psychometric properties. J. Consult. Clin. Psychol. 56, 893-897.

Beck, A.T., Brown, G., Berchick, R.J., Stewart, B.L., Steer, R.A., 1990. Relationship between hopelessness and ultimate suicide: a replication with psychiatric outpatients. Am. J. Psychiatry. 147, 190-195.

Beck, A.T., Haigh, E.A., 2014. Advances in cognitive theory and therapy: the generic cognitive model. Annu. Rev. Clin. Psychol. 10, 1-24.

Blumenthal, J.A., Burg, M.M., Barefoot, J., Williams, R.B., Haney, T., Zimet, G., 1987. Social support, type A behavior, and coronary artery disease. Psychosom. Med. 49, $331-340$.

Carter, G., Milner, A., McGill, K., Pirkis, J., Kapur, N., Spittal, M.J., 2017. Predicting suicidal behaviours using clinical instruments: systematic review and meta-analysis of positive predictive values for risk scales. Br. J. Psychiatry. 210, 387-395.

Chan, M.K., Bhatti, H., Meader, N., Stockton, S., Evans, J., O'Connor, R.C., Kapur, N., Kendall, T., 2016. Predicting suicide following self-harm: systematic review of risk factors and risk scales. Br. J. Psychiatry. 209, 277-283.

Chioqueta, A.P., Stiles, T.C., 2005. Personality traits and the development of depression, hopelessness, and suicide ideation. Personal. Indiv. Diff. 38, 1283-1291.

Clark, L.A., Watson, D., Mineka, S., 1994. Temperament, personality, and the mood and anxiety disorders. J. Abnorm. Psychol. 103, 103-116.

Costa Jr., P.T., 1991. Clinical use of the five-factor model: an introduction. J. Pers. Assess. 57, 393-398.

Eysenck, S.B., Eysenck, H.J., 1964. An improved short questionnaire for the measurement of extraversion and neuroticism. Life. Sci 3 (1962), 1103-1109.

Hamilton, M., 1960. A rating scale for depression. J. Neurol. Neurosurg. Psychiatry. 23, 56-62.

Hawton, K., Casanas, I., Comabella, C., Haw, C., Saunders, K., 2013. Risk factors for suicide in individuals with depression: a systematic review. J. Affect. Disord 147, $17-28$.

Hoertnagl, C.M., Hofer, A., 2014. Social cognition in serious mental illness. Curr. Opin. Psychiatry. 27, 197-202.

Holma, K.M., Holma, I.A., Melartin, T.K., Rytsala, H.J., Isometsa, E.T., 2008. Long-term outcome of major depressive disorder in psychiatric patients is variable. J. Clin. Psychiatry. 69, 196-205.

Kendler, K.S., 2017. The genealogy of major depression: symptoms and signs of melancholia from 1880 to 1900. Mol. Psychiatry. 22, 1539-1553.

Kovacs, M., Beck, A.T., 1978. Maladaptive cognitive structures in depression. Am. J. Psychiatry. 135, 525-533.

Kraemer, H.C., Kazdin, A.E., Offord, D.R., Kessler, R.C., Jensen, P.S., Kupfer, D.J., 1997. Coming to terms with the terms of risk. Arch. Gen. Psychiatry. 54, 337-343.

Kraemer, H.C., Gullion, C.M., Rush, A.J., Frank, E., Kupfer, D.J., 1994. Can state and trait variables be disentangled? A methodological framework for psychiatric disorders. Psychiatry Res. 52, 55-69. 
Liu, R.T., Kleiman, E.M., Nestor, B.A., Cheek, S.M., 2015. The hopelessness theory of depression: a quarter-century in review. Clin. Psychol. Sci. Pract. 22, 345-365.

Melartin, T.K., Rytsala, H.J., Leskela, U.S., Lestela-Mielonen, P.S., Sokero, T.P., Isometsa, E.T., 2002. Current comorbidity of psychiatric disorders among DSM-IV major depressive disorder patients in psychiatric care in the Vantaa depression study. J. Clin. Psychiatry. 63, 126-134.

Nakagawa, S. and Schielzeth, H., 2013. A general and simple method for obtaining R2 from generalized linear mixed-effects models. Methods in ecology and evolution / British Ecological Society. 4.

O'Connor, R.C., Nock, M.K., 2014. The psychology of suicidal behaviour. Lancet Psychiatry 1, 73-85.

Philippi, C.L., Koenigs, M., 2014. The neuropsychology of self-reflection in psychiatric illness. J. Psychiatr. Res. 54, 55-63.

Possel, P., Thomas, S.D., 2011. Cognitive triad as mediator in the hopelessness model? a three-wave longitudinal study. J. Clin. Psychol. 67, 224-240.
Ribeiro, J., Huang, X., Fox, K., Franklin, J., 2018. Depression and hopelessness as risk factors for suicide ideation, attempts and death: Meta-analysis of longitudinal studies. Br. J. Psychiatry 212 (5), 279-286. http://dx.doi.org/10.1192/bjp.2018.27.

Riihimaki, K.A., Vuorilehto, M.S., Melartin, T.K., Isometsa, E.T., 2014. Five-year outcome of major depressive disorder in primary health care. Psychol. Med. 44, 1369-1379.

Talarowska, M., Berk, M., Maes, M., Galecki, P., 2016. Autobiographical memory dysfunctions in depressive disorders. Psychiatry Clin. Neurosci. 70, 100-108.

Valtonen, H.M., Suominen, K., Haukka, J., Mantere, O., Arvilommi, P., Leppamaki, S., Isometsa, E.T., 2009. Hopelessness across phases of bipolar I or II disorder: a prospective study. J. Affect. Disord. 115, 11-17.

Young, M.A., Fogg, L.F., Scheftner, W., Fawcett, J., Akiskal, H., Maser, J., 1996. Stable trait components of hopelessness: baseline and sensitivity to depression. J. Abnorm. Psychol. 105, 155-165.

Zeiss, A.M., Lewinsohn, P.M., 1988. Enduring deficits after remissions of depression: a test of the scar hypothesis. Behav. Res. Therap. 26, 151-158. 